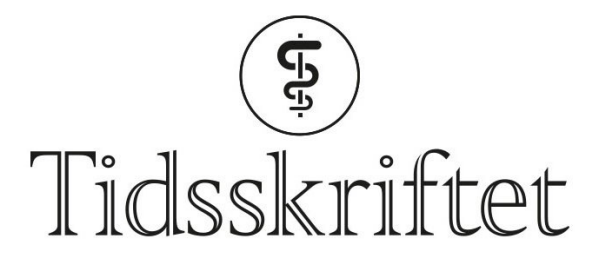

DEN NORSKE LEGEFORENING

\title{
En karriere utenom det vanlige
}

INTERVJU

TORI FLAATTEN HALVORSEN

E-post:Tori.F.Halvorsen@gmail.com

Odd Martin Vallersnes ble blitzer for å holde ut studiet. I over 20 år har han vært legevaktslege. På legevakten forsker han på rusmisbrukere. Snart er han vel professor.

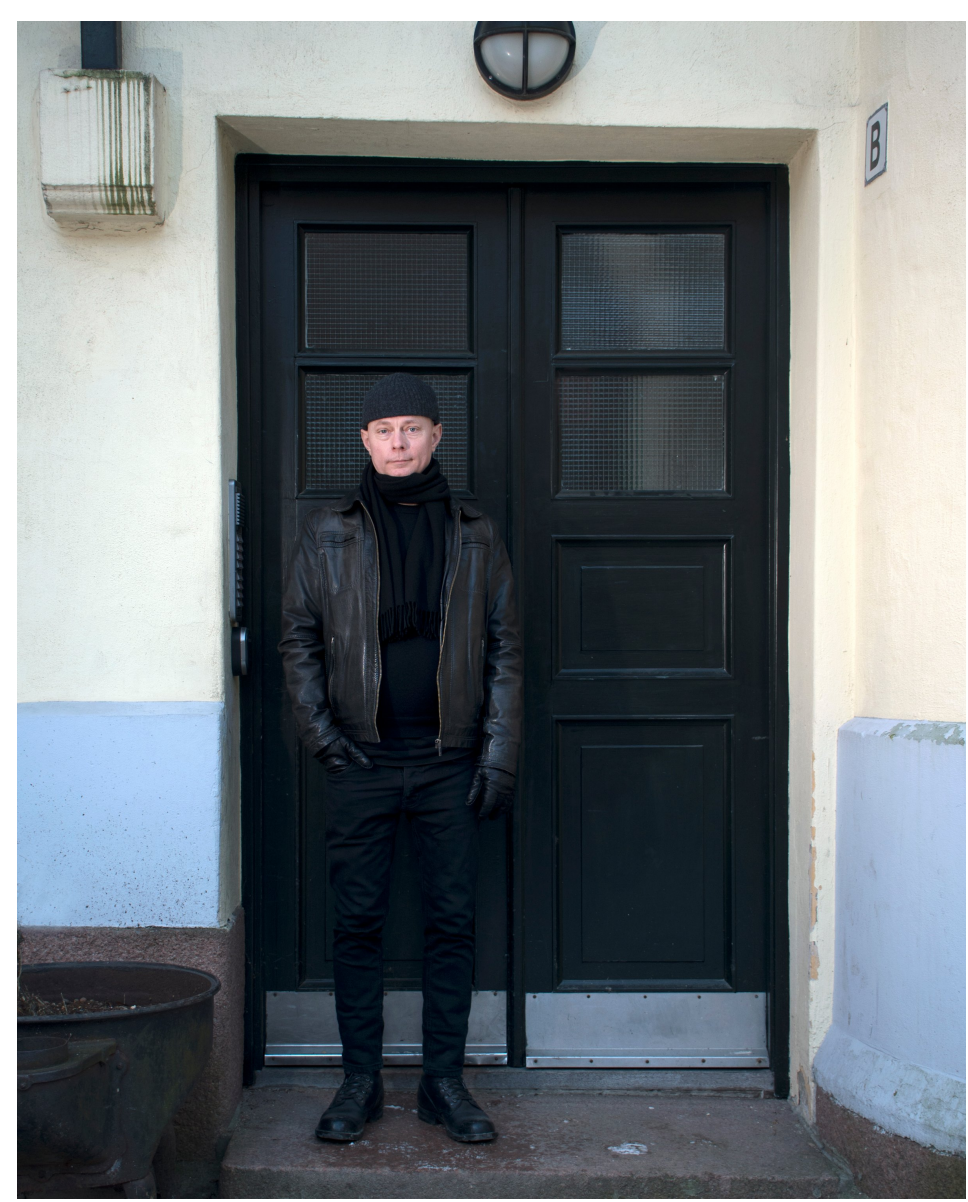

Foto: Tori Flaatten Halvorsen

For over 150 år siden åpnet Krohgstøtten sykehusdørene for fattigfolk og kronisk syke. I 1900 ble sykehuset ved Akerselva omgjort til hovedstadens legevakt. I likhet med bygningen, ser Odd Martin Vallersnes akkurat ut som han gjorde da han for 23 år siden kom inn på vaktrommet på allmennlegevakten for første gang. Hodet er like glattbarbert og kroppen nesten like tynn. Tenksomheten før han svarer, er der fortsatt. Svarene er like velformulerte. Også det langsomme tempoet i bevegelsene og gangen er som før. Den noe mystiske og 
uforanderlige mannen har tatt doktorgrad på storbyens rusmisbrukere og holder foredrag på universiteter og høyskoler like gjerne som på Litteraturhuset og Rockefeller. Kleskoden forblir svart, selv om skinnjakken ikke lenger har nagler eller flere glidelåser enn nødvendig. Den sosiale kontakten med kullkameratene fra det «morsomme 89-kullet i Oslo» og folket fra det den gang okkuperte Blitzhuset på 8o-9o-tallet er fortsatt viktig. Karrieren som sanger og tekstforfatter i flere punkband er over. Sigaretten er stumpet. Men tålmodigheten, omtanken og det humanistiske menneskesynet har ikke sluknet.

\section{Doktorgrad fra legevakten}

Det startet med at han avtjente siviltjenesten på legevakten. Det ble en selvfølge å fortsette. Andre leger gikk inn i ulike spesialiteter, men Odd Martin fant ingen grunn til å gjøre som dem. Ingen arbeidsdag var lik og alle var meningsfylte. Etter omkring 10 år ga avdelingsoverlegen opp å få han med i ledelsen. Under en medarbeidersamtale ytret han et $\emptyset$ nske om å undervise. Forskningserfaring ble avgjørende.

\section{Odd Martin Vallersnes}

Født 1969 i Haugesund

Cand.med. Universitetet i Oslo 1996

Lege ved Legevakten i Oslo siden 1998

Fastlege ved Stovner legesenter 2008-10

Spesialist i allmennmedisin 2010

Ph.d. Universitetet i Oslo 2017

Førsteamanuensis i allmennmedisin ved Universitetet i Oslo fra 2017

- Det fascinerte meg at det enkle obs-skjemaet som hadde vært i bruk på obsrommet i årevis, kunne være et så godt redskap for å oppdage når de akutte rustilstandene bikket over til å bli virkelig farlige.

I starten følte han seg utrygg på tilstander som utviklet seg på en annen måte enn forventet, for eksempel grunnet samtidig inntak av ulike rusmidler. Etterhvert stolte han på det to siders lange verktøyet med Glasgow Coma Scale, respirasjonsfrekvens, saturasjon og pupillestørrelse som det mest sentrale. Med tid, antidot og en sjelden gang glukose, kunne han behandle de fleste ut av den akutte hjelpeløsheten. Det trodde alle. Han ville finne ut om det stemte.

\section{Enkle hjelpemidler}

Resultatene av forskning på vel 2500 akutte ruspasienter som kom på legevakten i løpet av ett år, var oppløftende. Hovedkonklusjonen var at mannskapet på legevakten klarte å berge vel $80 \%$ av pasientene gjennom en observasjon på maks fire timer på et enkelt utstyrt «obsrom». De resterende ble videresendt til sykehus. Ingen døde. Odd Martin har aldri hørt om noen som har dødd på obsrommet.

- Er du stolt av resultatene?

- Det var gøy å vite at vi gjorde ting rett. Men så måtte vi tenke neste steg. De fleste akutte rustilfellene på legevakten handler om andre ting enn et hendelig uhell i fylla. De unge jentene og guttene med alkohol- eller blandingsintoksikasjon er ofte på kanten av stupet. Der kan vi gjøre en forskjell!

Rusakuttmottaket på Aker åpnet og legevakten satte i gang med en tverrfaglig oppfølgingsgruppe. Odd Martin representerer fortsatt legene. Mange blir henvist til spesialisthelsetjenesten eller får råd om å oppsøke fastlegen.

De unge jentene og guttene med alkohol- eller blandingsintoksikasjon er ofte på kanten av stupet. Der kan vi gjøre en forskjell! 
- Avmaktsfølelsen vi hadde før, har blitt mye mindre når vi ser det nytter.

Ny forskning, som Odd Martin også fronter gjennom kronikker, foredrag og intervjuer, viser at mange av pasientene møter i spesialisthelsetjenesten eller får oppfølging hos fastlegene.

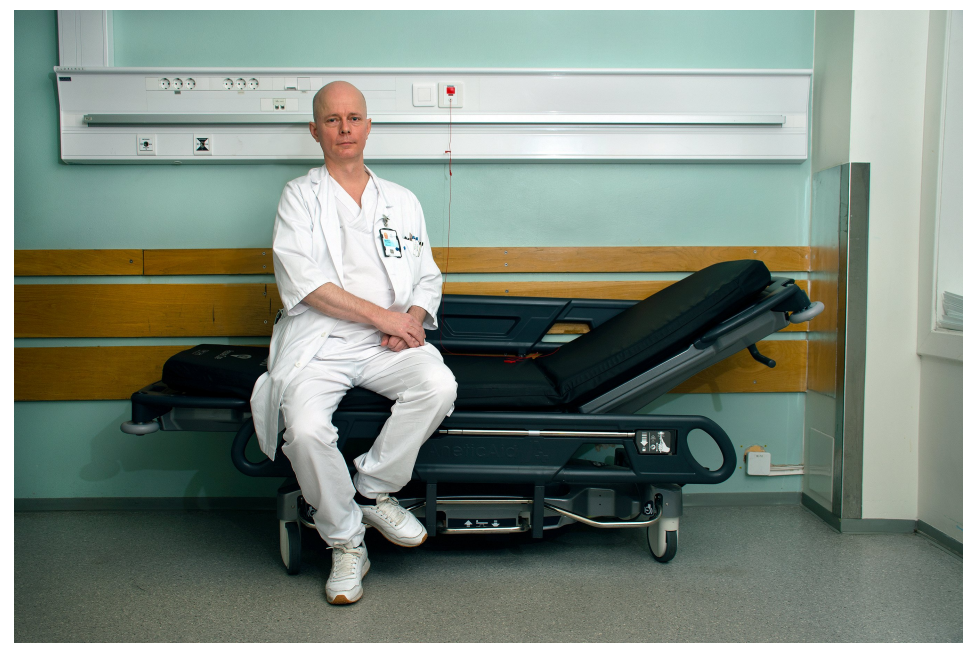

Obsrommet er svcert enkelt utstyrt. En tralle med blodtrykksapparat og puls- og saturasjonsmåler er dog på plass så snart det kommer en pasient med akutt forgiftning. Foto: Tori Flaatten Halvorsen

- Får du lyst til å følge dem opp selv?

- I de to årene jeg var fastlege, trivdes jeg med de gode samtalene med pasientene om eksistensielle spørsmål. Det var fint å følge dem over tid. Jeg kunne ha blitt der ute, men forskningsprosjektet var i startfasen. Med to år på fastlegekontor, så jeg den gode jobben kollegaene mine gjorde med pasienter som hadde vært på legevakten. Det var betryggende.

\section{Fortsatt legevaktjobbing}

Odd Martin har nå $50 \%$ stilling på legevakten som skiftleder ved klinikken, i tillegg til en del ekstraoppgaver innen veiledning og annet. Det er fortsatt jobb hver fjerde helg, men nå uten nattevakter. Han liker å styre et vaktlag når det uforutsette skjer, men kan ikke tenke seg å jobbe høyere opp i ledelsen eller administrasjonen. Lagånden snakker han varmt om. Alle i ledelsen har tidligere jobbet klinisk på huset. På morgenmøtene vet alle hvordan det er å stå med vanskelige kliniske situasjoner midt på natten. En spørrerunde blant kollegaer avslører at Odd Martin er god til å finne det rette tidspunktet for å gi kollegaene nødvendige faglige tilbakemeldinger. De gir han også mye av æren for at forskerkontoret stadig blir brukt av flere.

\section{Pasienten i fokus}

- Det er ulike folk som ramler inn på legevakten midt i Oslo sentrum?

- Alt som ikke passer noe annet sted, er legevaktens bord. Om en nyansatt ikke er innforstått med det, tar det ikke lang tid før han eller hun slutter, forklarer Odd Martin.

Alt som ikke passer noe annet sted, er legevaktens bord

- Dere er ikke lønnet etter antallet konsultasjoner som gjennomføres?

- Det kommer innimellom kollegaer som foreslår nettopp det, men på vår arbeidsplass er det helt umulig. Det ville ha ødelagt samholdet i vaktlaget.

\section{Stadig nye leger}

- Blir du lei av at det stadig slutter kollegaer?

- Det var trist i begynnelsen, men jeg har lært å leve med det. Søkelistene er så lange at vi kan plukke de beste når andre slutter, sier mannen som gjerne vil være med å forme 
nyutdannede leger. I likhet med det han formidler i artikkelen «Legekunst på legevakt» i Tidsskriftet i 2016, fokuserer han på at legen må møte pasientens bekymring med omsorg. Han understreker at den syke må få snakke ut og at legen må få tatt de undersøkelsene som trengs for en konklusjon, men heller ikke flere. I artikkelen refererer han til forskning som viser at pasienter snakker sjelden mer enn to minutter, hvis de ikke blir avbrutt. Språket i artikkelen er nøkternt og presist, men samtidig uvanlig litterært. Et eksempel er: «Undervurdér aldri betydningen av å ta på pasienten. Å ta på er å røre ved».

- Det er befriende lite high-tech i legevaktmedisinen og det passer meg bra, smiler Odd Martin.

\section{Førsteamanuensis}

Odd Martin jobber halv tid på Avdeling for allmennmedisin ved Universitetet i Oslo. Listen over artikler er lang. Mest om rus, men også om feildiagnostisering og overbehandling på legevakt. Alt er temaer han underviser i for medisinerstudenter og paramedisinere på høyskoler eller på kurs og kongresser. På YouTube finnes opptak fra «Viten på lørdag» på Litteraturhuset i Oslo, der han snakker omsorgsfullt om ruspasientene i byen. Men i sosiale medier finner du ikke navnet hans. Han trenger å trekke seg tilbake. Da går han opp trappene til loftsleiligheten i en vel 100 år gammel bygård i Gamlebyen. Der bor han med sin kone Hilde og alle bøkene.

\section{Kunnskap og engasjement}

Veggen i stuen minner om et bibliotek: romaner, historiebøker, idéhistoriebøker og politisk litteratur. Hjemme hos familien i Haugesund har det informerte standpunktet alltid vært verdsatt. Noen ganger blir diskusjonene intense, men samholdet i storfamilien har likevel alltid vært sterkt. Faren har sittet på Stortinget for Høyre og vært ordfører og røntgenlege i Haugesund. Odd Martin har holdt seg til den røde politiske fargen.

Aktivistrollen har vært mer tiltrekkende enn det å jobbe for et partiprogram. Kampen mot undertrykking og utbytting, mot rasisme, apartheid og nynazisme ble viktig da han i 1987 flyttet til Oslo. Attenåringen så dystert på fremtiden. Det var viktig å «kunne gjøre noe ordentlig i en eventuell postapokalyptisk tid» som han selv sier. Snekker, mekaniker eller sykepleier var alternativer, men en senebetennelse etter en lagerjobb satte en stopper for yrker som var for fysiske. Tidligere hadde det aldri vært et alternativ å følge i fars og farfars fotspor. Nå kom legeyrket opp som et godt alternativ både for han selv og for hva samfunnet ville trenge i den usikre tiden.

\section{Blitzer og aktivist}

Han trengte en motvekt til et studentmiljø han antok ville bli for homogent og lukket, og søkte et fellesskap utover samværet med samboeren Hilde, som hadde dukket opp på en balkong på Oppsal en sen nattetime våren før. Så en dag før oppstart på studiet, spaserte haugesunderen helt alene inn på Blitzhuset og meldte seg til kjøkkentjeneste. Han ble mottatt med åpne armer. 


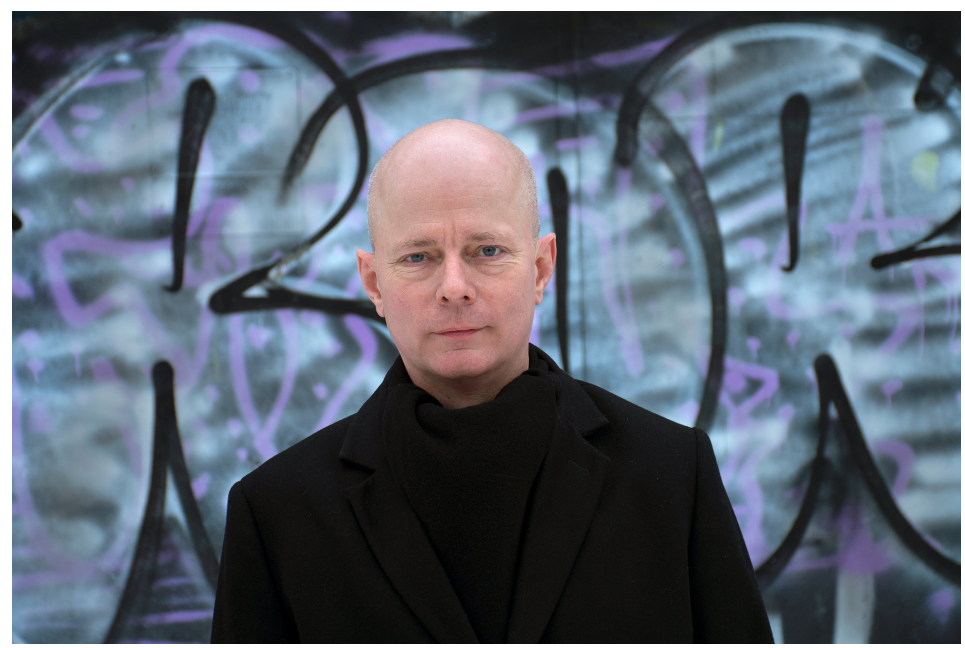

Foto: Tori Flaatten Halvorsen

- Blitz var et sted for alle typer mennesker. Skarpe folk som var opptatt av politikk og musikk!

Flere ganger i uken sto han i oppvasken eller serverte i kafeen i det fargerike, nedtaggete og kontroversielle huset i Pilestredet. Erfaringene etter et mislykket år som forfatterspire, kom godt med i arbeidet med å skrive politiske tekster både til kontroversielle aksjoner i hovedstadens gater og for punkebandet «Dead Gerhardsens». Synge kunne han ikke, men vokalist ble han likevel. Hard musikk i høyt tempo og Odd Martin som vekselsvis synger og skriker «ingen nazister på våre gater» finnes fortsatt på YouTube. Den ellers tenksomme Odd Martin viser seg i en helt annen versjon der han står på ytterkanten av scenen foran et begeistret publikum hoppende i takt. Med en tilsynelatende selvsikker mine lar han fansen synge noen strofer inn i mikrofonen, før han selv gjentar med hes stemme: «Ingen nazister på våre gater».

- Du har en evne til å forholde deg til mange miljøer og mennesker, men hvordan balanserer du mellom den mer aggressive politiske Odd Martin og den sindige forskeren og klinikeren?

- Drivkraften har aldri vært aggresjon, men alvor. Samtidig var politisk aktivisme og band også helt klart gøy. Jeg er opptatt av å gjøre ting skikkelig. Alle skal møtes på skikkelig vis. Legevakt er alvor, samtidig er det gøy å være lege ved Legevakten i Oslo.

\section{Tvilen dukker opp}

Det ble flere konserter og aksjoner på blitzeren. Samtidig fortsatte han de lange diskusjonene i kantinen på medfak sammen med kullkamerater som argumenterte godt for seg. Smarte og morsomme folk som alle visste at Odd Martin brukte mye tid på Blitzhuset. Legestudenten besto fysiologieksamen, men forståelsen for stoffet var magert. Han ble i tvil om hvor ferden skulle gå videre, og tok idéhistorie grunnfag. Hvordan samfunnets strukturer har utviklet seg gjennom historien måtte utforskes. Men etter et år på det humanistiske fakultet, bestemte den ganske så sta mannen at han likevel ikke ville gi seg. Det var tid for kliniske fag. Følelsen av at han kunne "gjøre noe» kom nærmere. Hullene i fysiologiforståelsen var likevel et hinder.

- Så da var det bare å lese hele fysiologipensumet igjen. Jeg måtte jo vite hva det hele handlet om når jeg skulle møte virkelige pasienter.

\section{Turnus før legevakten}

Studiet ble mer lystbetont, men turnusen i Fredrikstad ble tyngre enn han hadde tenkt seg. Ikke på grunn av jobben, men fordi han valgte å bli boende i Oslo for å kunne fortsette punkebandkarrieren. Så var det Finnmark i distriktsturnus. Bandet ble igjen i Oslo, men Hilde ble med til Lakselv. Da paret ved juletider var på farten sørover igjen, tok en av bygdas 
unge menn Hilde til side. Han ville fortelle henne at det var lenge siden de hadde hatt en så grei turnuslege sørfra. Kort tid etterpå går Odd Martin blendet av den lave januarsolen opp langs Akerselva til Storgata. I stedet for å kle seg i grønne kamuflasjeklær og lære seg våpenbruk sammen med jevnaldrende, tar han på seg hvite klær for å gjøre en jobb for storbyens befolkning. På obsrommet lytter han til de erfarne som vektlegger det mest sentrale for å holde liv i en ruset person. Lite visste den beskjedne unge mannen at han senere selv skulle utforme et forskningsprosjekt som ble første steg $\mathrm{i}$ en akademisk karriere. Om Odd Martin blir den første professoren fra Oslo Legevakt, vet ingen. Oddsen er på hans side.

Publisert: 22. mars 2021. Tidsskr Nor Legeforen. DOI: 10.4045/tidsskr.21.0077

(C) Tidsskrift for Den norske legeforening 2020. Lastet ned fra tidsskriftet.no 